$14,7 \mathrm{mg} /$ tuần cao hơn có ý nghĩa so với bênh nhân có chỉ số $B M I<23 \mathrm{~kg} / \mathrm{m}^{2}$ là $10,1 \mathrm{mg} /$ tuần $(p<0,05)$. Không có sự khác biệt về liều thuốc theo giới và nguyên nhân dùng thuốc acenocoumarol ở nhóm nghiên cứu. Kết quả này tương đồng với các nghiên cứu trong nước và trên thế giới khi tuổi bệnh nhân càng cao hoạt động của hệ thống enzym tại gan cũng như chức nằng của thận suy giảm do vậy làm chậm sự thanh thải của thuốc ra khỏi cơ thể [6]. Ngoài ra bệnh nhân có chỉ số BMI càng cao đòi hỏi liều thuốc chống đông càng lớn.

Bệnh nhân mang kiểu gen đồng hợp biến dị VKORC1-1639AA có yêu cầu liêuu chống đông thấp nhất $10,3 \mathrm{mg} /$ tuần, bệnh nhân mang kiểu gen dại GG có yêu cầu liều cao nhất 21,0 $\mathrm{mg} / \mathrm{tuần}(\mathrm{p}<0,05)$. Đối với kiểu gen đồng hợp biến dị VKORC1 1173TT có yêu cầu liều chống đông (10,2mg/tuân) thấp hơn có ý nghĩa so với bênh nhân mang kiểu gen dị hợp $(15,5 \mathrm{mg} /$ tuần) và đồng hợp kiểu dại (21,7mg/tuần) với $p<0,05$. Không có sự khác biệt về liều chống đông giữa các bệnh nhân mang kiểu gen CYP2C9*1*3 và $* 1 * 1$. Điều này hoàn toàn phù hợp với các nghiên cứu trong nước và quốc tế khác khi cho rằng sự xuất hiện các alen biến thể VKORC11639G >A, 1173C>T làm giảm tổng hợp enzym đích của acenocoumarol trong quá trình chuyển hóa, do vậy bệnh nhân cần một liều chống đông thấp hơn bình thường đã đạt hiệu quả điều trị [7]. Với đa hình gen CYP2C9*3 xuất hiện với tần số thấp trong nghiên cứu do vậy không thấy được mối liên quan giữa đa hình này và liều thuốc acenocoumarol ở quần thể nghiên cứu.

\section{KẾT LUÂ̂N}

Tỷ lệ alen biến dị của VKORC1-1639G>A,
$1173 C>T$ và CYP2C9*3 lần lướt là $0,911,0,901$ và 0,023 . Có mối liên quan giữa, tuổi, $B M I$ và đa hình gen VKORC1-1639G $>A, 1173 C>T$ với liều thuốc chống đông acenocoumarol ở các bệnh nhân mắc các bệnh lý về tim mạch tại bệnh viện Trung ương Thái Nguyên $(p<0,05)$.

\section{TÀI LIẸU THAM KHẢO}

1. Krishna Kumar D, Madhan S, Balachander J, et al (2013). Effect of CYP2C9 and VKORC1 genetic polymorphisms on mean daily maintenance dose of acenocoumarol in South Indian patients. Thromb Res, 131(4), 363-367.

2. Ajmi M, Omezzine A, Achour S, et al (2018). Influence of genetic and non-genetic factors on acenocoumarol maintenance dose requirement in a Tunisian population. Eur J Clin Pharmacol, 74(6), 711-722.

3. Buzoianu A.D, Militaru F.C, Vesa S.C, et al (2013). The impact of the CYP2C9 and VKORC1 polymorphisms on acenocoumarol dose requirements in a Romanian population. Blood Cells Mol Dis, 50(3), 166-170.

4. Elkhazraji A, Bouaiti E.A, Boulahyaoui $H$, et al (2018). Effect of CYP2C9, VKORC1, CYP4F2, and GGCX gene variants and patient characteristics on acenocoumarol maintenance dose: Proposal for a dosing algorithm for Moroccan patients. Drug Discoveries \& Therapeutics, 9.

5. Pham T.T, Nhung P.T.H, Ta V.T, et al (2019). VKORC1 and CYP2C9*3 Polymorphisms and Their Impacts to Acenocoumarol Dosage in Vietnamese Heart Valve Replacement Patients $† .10$.

6. Pop T.R, Vesa S.C, Trifa A.P, et al (2013). An acenocoumarol dose algorithm based on a SouthEastern European population. Eur J Clin Pharmacol, 69(11), 1901-1907.

7. Varnai R, Sipeky C, Nagy L, et al (2017). CYP2C9 and VKORC1 in therapeutic dosing and safety of acenocoumarol treatment: implication for clinical practice in Hungary. Environ Toxicol Pharmacol, 56, 282-289.

\title{
MộT Số YẾU TỐ LIÊN QUAN ĐẾN TÁI NGHIÊN RƯỢU Ở NHỮNG BỆNH NHÂN ĐÃ ĐƯợC ĐIỀU TRI TẠI VIÊ̂N SỨC KHỎE TÂM THẦN
}

\author{
Nguyễn Thị Phưong Mai ${ }^{2}$, Nguyễn Văn Tuấn ${ }^{1,2}, K^{2}$ im Bảo Giang ${ }^{1}$
}

\section{TÓM TẮT}

Mục tiêu: Phân tích một số yếu tố liên quan đến tái nghiện rượu ở những bệnh nhân đã được điều trị

\footnotetext{
${ }^{1}$ Trường Đại học Y Hà Nọi

${ }^{2}$ Viện Sức khoé Tâm thần - Bênh viện Bạch Mai

Chịu trách nhiệm chính: Nguyễn Thị Phương Mai

Email: npmmisa@gmail.com

Ngày nhân bài: 29.12.2020

Ngày phản biên khoa hoc: 25.2.2021

Ngày duyệt bài: 8.3 .2021
}

tại Viện Sức khoẻ Tâm thần (VSKTT). Đối tượng và phương pháp: Nghiên cứu theo dối dọc, phân tích một số yểu tố liên quan đến tái nghiện rượu ở bệnh nhân khi nằm viện, tại các thời điểm một tháng, ba tháng và sáu tháng sau khi ra viện. Thời gian nghiên cứu: 01/2018 - 02/2020. Kết quả: 71,29\% đối tương nghiên cứu đã tái nghiện rượu sau khi cai nghiện, tỷ lệ tái nghiên cao nhất trong tháng đầu sau ra viẹn $(35,64 \%)$, lý do tái nghiện rượu chủ yếu là do thèm nhớ $(76,39 \%)$. Tiền sử gia đình có người lạm dụng, nghiện rượu, gia đình bệnh nhân không phản đối việc sữ dụng rượu, sang chấn tâm lý và sự xuất hiện đồng 
thời rối loạn trầm cảm làm tăng khả năng tái nghiện rượu. Kết luận: Có nhiều yếu tố liên quan đến việc tái nghiện rượu do đó các bệnh nhân sau khi cai nghiện rượu cần được áp dụng điều trị chống tái nghiện lâu dài tại cộng đồng.

Từ khóa: tái nghiện rượu, các yếu tố liên quan đến tái nghiện rượu

\section{SUMMARY \\ SOME FACTORS RELATED TO ALCOHOL- DEPENDENT RELAPSE OF INPATIENTS AT NATIONAL INSTITUTE OF MENTAL HEALTH \\ Objective: To analyze a number of factors related to alcohol- dependent relapse in patients who have been treated at the National Institute of Mental Health. Subjects and methods: A follow-up study, analyzing several factors related to alcohol-dependent relapse in patients at hospital, at the point of one month, three months and six months after being discharged from the hospital. Results: $71.29 \%$ of study subjects relapsed after detoxification, the highest rate of relapse in the first month after treatment $(35.64 \%)$. The reason for relapse was mainly due to craving (76.39\%). A family history of alcohol abuse and dependence, patients' family who did not oppose alcohol use, stress, and the simultaneous occurrence of depressive disorders increase the rate of relapse. Conclusion: There are many factors related to the relapse of alcohol dependence so that patients after being discharged from the hospital should be treated for long-term} relapse prevention in the community.

Keywords: alcohol- dependent relapse, factors related to alcohol- dependent relapse

\section{I. ĐĂT VẤN ĐỀ}

Ở hầu hết các nền văn hóa, rượu là chất được sử dụng thường xuyên nhất, đóng góp đáng kể vào tỷ lệ bệnh tật và tử vong. Theo báo cáo toàn cầu về rượu và sức khoẻ của Tổ chức $Y$ tế Thế giới năm 2016, khoảng ba triệu trường hợp tử vong, chiếm $5,3 \%$ tử vong toàn câu, 132,6 triệu DALYs (số năm sống được điều chỉnh theo tình trang khuyết tật) hoặc 5,1\% gánh nặng bệnh tật và thương tích toàn câuu do tiêu thụ rượu ${ }^{1}$.

Nghiên rượu là bênh lý tái phát man tính với nhiều yểu tố dẫn đến tái nghiện. Những yếu tố liên quan đến tái nghiện rượu có thể là các đặc điểm nhân khẩu xã hội học, đặc điểm sử dụng rượu cũng như tính chất đồng bệnh lý giữa nghiện rượu và một số rối loạn tâm thần. Những người nghiện rượu độc thân có khả năng tái nghiện cao hơn những người đã kết hôn². Tái nghiện cũng có xu hướng nghiêm trọng hơn đối với nhóm thất nghiêp ${ }^{3}$. Nguy cơ các vấn đề về rượu gấp ba đến bốn lần ở người thân của những người rối loạn sử dụng rượu ${ }^{4}$. Bên cạnh đó, nhiều nghiên cứu đều nhận định việc thèm nhớ rượu mạnh mẽ là một trong những yếu tố liên quan đến tái nghiện rượu ${ }^{5}$. Ngoài ra, nghiện rượu và các rối loạn tâm thần đồng diễn có nguy cơ làm cho cả hai rối loạn nặng thêm và tái phát nhiều hơn.

Ở Việt Nam đến nay chưa có nghiên cứu nào tìm hiểu sâu về vấn đề tái nghiện rượu ở những người đã được cai nghiện tại cở sở y tế. Chúng tôi tiến hành nghiên cứu này nhằm phân tích một số yếu tố liên quan đên tái nghiện rượu ở những bệnh nhân đã được điều trị tại Viện Sức khoẻ Tâm thần.

\section{II. ĐỐI TƯỢNG VÀ PHƯƠNG PHÁP NGHIÊN CỨU}

- Đôi tượng nghiên cứu: 101 bệnh nhân rối loạn tâm thẩn và hành vi do sử dung rượu điều trị nội trú tại Viện Sức khoẻ Tâm thần, thỏa mãn tiêu chuẩn chẩn đoán nghiện rượu theo Bảng Phân loại bệnh Quốc tế về các rối loạn tâm thần và hành vi (ICD-10F) 1992 của Tổ chức $Y$ tế Thế giới. Thời gian nghiên cứu: 01/2018 02/2020.

- Phương pháp nghiên cứu: Nghiên cứu theo dõi dọc, phân tích một số yếu tố liên quan đến tái nghiện rượu thông qua phỏng vấn trực tiếp bệnh nhân khi nằm viện, tại thời điểm một tháng, ba tháng và sáu tháng sau khi ra viện. Xử lý số liệu bằng phần mềm Stata 15.

\section{KẾT QUẢ NGHIÊN CỨU}

\section{Tỉ lệ tái nghiện rượu}

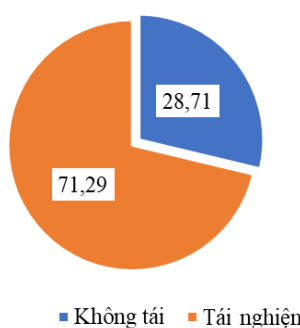

Biểu đồ 1: Tỷ lệ tái nghiện rượu

- Số đối tượng tái nghiện rượu là 72/101, chiếm tỷ lê cao $71,29 \%$

\section{Thời gian tái nghiện rượu sau khi cai}

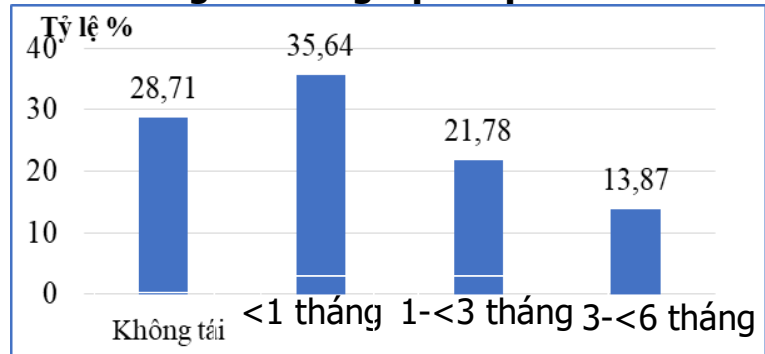

Biểu đồ 2: Thời gian tái nghiện rượu sau khi cai 
- Tỷ lệ tái nghiện rượu cao nhất trong khoảng tháng đầu sau cai nghiện rượu (35,64\%), sau đó giảm dần theo thời gian.

\section{Lý do tái nghiện rượu}

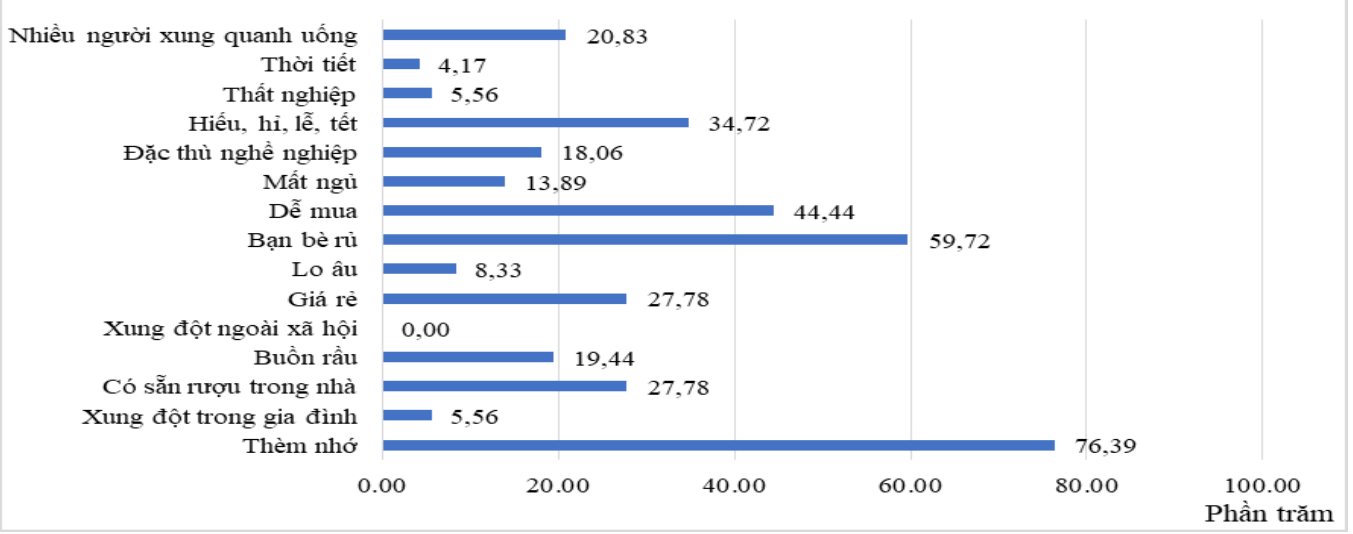

\section{Biểu đồ 3: Lý do tái nghiênn rượu}

Có rất nhiều lý do các đối tượng tái nghiện rượu, chiểm tỷ lệ lớn nhất là do thèm nhớ: 76,39\%, tiếp đó là do ban bè rủ: 59,72\%.

4. Một số yếu tố liên quan đến tái nghiện rượu

Bảng 4.1: Mối liên quan giữa đặc điểm nhân khẩu học, đặc điểm sử dụng rượu và rôí loạn tâm thân đồng diên với tái nghiện rượu trong phân tích hồi quy logistic đa biến

\begin{tabular}{|c|c|c|c|c|c|}
\hline Biến số (nhóm tham khảo) & & OR & $\mathbf{p}$ & \multicolumn{2}{|c|}{ 95\% CI } \\
\hline Tuổi bệnh nhân (< 40 tuối) & Tuổi $\geq 40$ & 0,89 & 0,922 & 0,09 & 8,78 \\
\hline Hôn nhân (Kềt hôn) & Độc thân/ly dì/ goá & 0,30 & 0,154 & 0,06 & 1,56 \\
\hline Học vấn (Dưới PTTH) & Từ PTTH trở lên & 1,60 & 0,755 & 0,08 & 30,20 \\
\hline Nghề nghiệp (Có nghề nghiệp) & Thất nghiệp & 1,12 & 0,944 & 0,05 & 25,47 \\
\hline Gia đình có người nghiện rượu (Không) & Có & 45,31 & 0,001 & 4,89 & 419,67 \\
\hline Gia đình phản đối mạnh mẽ việc sử dụng rượu (Có) & Không & 8,99 & 0,017 & 1,49 & 54,29 \\
\hline Tuối bắt đầu sứ dung rươu ( $<30$ tuối) & Từ 30 tuổi & 0,53 & 0,55 & 0,07 & 4,23 \\
\hline Thời gian nghiện rượu (< 20 năm) & Từ 20 năm & 0,31 & 0,16 & 0,06 & 1,59 \\
\hline Số lần đã cai nghiện (< 4 lần) & Z 4 lần & 6,96 & 0,052 & 0,98 & 49,48 \\
\hline Tuân thủ điều trị (Không) & Tuân thủ 3 thời điếm & 0,59 & 0,559 & 0,10 & 3,47 \\
\hline \multirow{3}{*}{ Rôi loạn trầm cảm (Không) } & Nhẹ & 10,18 & 0,019 & 1,46 & 71,04 \\
\hline & Vừa & 3,36 & 0,493 & 0,12 & 106,62 \\
\hline & Nặng, rất nặng & 1 & & & \\
\hline \multirow{3}{*}{ Rối loạn lo âu (Không) } & Nhe & 2,43 & 0,547 & 0,13 & 43,88 \\
\hline & Vừa & 1 & & & \\
\hline & Nặng, rất nặng & 1 & & & \\
\hline Rối loạn giấc ngủ (Không) & Có & & & & \\
\hline Thèm nhớ (Khồng) & Có & & & & \\
\hline Áp lực nhóm (Không) & Có & 1,70 & 0,531 & 0,32 & 8,94 \\
\hline Sang chấn tâm lý (Không) & Có & 18,17 & 0,012 & 1,87 & 176,06 \\
\hline
\end{tabular}

- Những bệnh nhân với tiền sử gia đình có người nghiện rượu có khả năng tái nghiện gấp 45,31 lần; 95\% CI: 4,89 - 419,67.

- Những bệnh nhân có gia đình không phản đối mạnh mẽ việc sử dụng rượu làm tăng khả năng tái nghiện lên 8,99 lần so với việc gia đình phản đối mạnh mẽ việc sử dụng rượu; $95 \%$ CI: $1,49-54,29$.

- Những bệnh nhân có trầm cảm nhẹ có khả năng tái nghiên gấp 10,18 lần những bệnh nhân không trầm cảm; 95\% CI: 1,46 - 71,04.

- Những bệnh nhân có sang chấn tâm lý có khả năng tái nghiện gấp 18,17 lần bệnh nhân không có sang chấn tâm lý; 95\% CI: 1,87 176,06

\section{BÀN LUÂN}

1.Tỉ lệ tái nghiện rượu. Khi theo dõi việc tái nghiện rượu ở 101 đối tượng nghiên cứu điều 
trị tại VSKTT, có 71,29\% đối tượng tái nghiện rượu. Kết quả này tương tự nhiều nghiên cứu trên thế giới nhận thấy tỷ lệ tái nghiện rượu sau khi điều trị nôi trú hoăc ngoai trú dao động từ $50 \%$ đến $90 \%{ }^{2,6}$. Như vậy, tỷ lệ tái nghiện rượu nhìn chung vẫn ở mức tương đối cao.

2. Thời gian tái nghiện rượu sau khi cai. Tỷ lệ tái nghiện rượu cao nhất trong khoảng một tháng đầu sau cai nghiện (35,64\%), sau đó giảm dần theo thời gian. Nhóm đối tượng nghiện rượu của chúng tôi dường như có tỷ lệ tái nghiện cao xảy ra sớm hơn so với các nhóm đối tượng nghiện rượu trong các nghiên cứu khác, thường có tỳ lệ tái nghiện cao nhất trong ba tháng đâu sau điểu trị ${ }^{4}$. Điều này đòi hỏi cần có các biện pháp điêu trị dự phòng tái nghiện tích cực cho các đối tượng nghiện rượu ngay sau khi cai nghiện.

3. Lý do tái nghiện rượu. Chúng tôi nhận thây có rất nhiêu lý do mà những người tái nghiện rượu đưa ra để giải thích cho việc tái sử dụng rượu thường xuyên của mình, trong đó chiếm tỷ lệ lớn nhất là do thèm nhớ $(76,39 \%)$. Một số nghiên cứu trên thế giới cũng đưa ra nhận xét như chúng tôi. Theo Evren và cộng sứ, thèm nhớ là nguyên nhân quan trọng nhất dấn đến tái nghiện rượu ${ }^{5}$. Thực tế cũng đã có nhiều nghiên cứu về hoá dược và các liệu pháp tâm lý can thiêp tác động làm giảm cảm giác thèm nhớ cho thấy hiệu quả điều trị chống tái nghiện rượu.

4. Một số yếu tố liên quan đến tái nghiện rượu. Khi phân tích hồi quy logistic đa biến, chúng tôi nhận thấy tiền sử gia đình có người lạm dụng, nghiện rượu làm tăng khả năng tái nghiện lên 45,31 lân, 95\% CI (4,89 $419,67), p<0,05$ (bảng 3.40). Kết quả trên đòi hỏi người thây thuốc trong quá trình điều trị cũng cần quan tâm tìm hiểu và tư vấn cho cả những người thân, người sống cùng gia đình bệnh nhân, để nâng cao hiệu quả phòng chống tái nghiên. Bên canh đó, việc gia đình không phản đối mạnh mẽ việc sử dụng rượu làm tăng khả năng tái nghiện lển 8,99 lần so với việc gia đình phản đối mạnh mẽ việc sử dụng rượu, $95 \%$ CI $(1,49-54,29), p<0,05$. Điêu này chứng tỏ thái độ quyết liệt của gia đình trước việc sử dụng rượu của bênh nhân cũng hết sức quan trọng. Vì vậy, luôn cần có sự phối hợp tích cực nhiều hơn nữa từ gia đình của những người nghiện rượu, góp phần giúp đem lại hiệu quả trong quá trình hồi phục sau cai nghiện rượu.

Khi xem xét mối liên quan giữa sang chấn tâm lý với việc tái nghiện rượu, nghiên cứu của Sureshkumar và cộng sự (2017) khẳng định nhiều sự kiện gây stress trong quá khứ có liên quan với tái nghiện7. Nghiên cứu của chúng tôi cũng nhận thấy mối liên quan này, những người nghiện rượu gặp sang chấn tâm lý có nguy cơ tái nghiện gấp 18,17 lần bệnh nhân không có sang chấn tâm lý, với khoảng tin cậy $95 \%$ CI $(1,87$ $176,06), p<0,01$. Phần lớn những người nghiện rượu sau khi cai nghiện, trở về với gia đình và cộng đồng gặp rất nhiều áp lực tâm lý xã hội. Những lúc đó một số người vẫn xem rượu như cách để giải quyết các vấn đề khó khăn trong cuô̂c sống và dễ dàng sử dụng trở lại.

Nghiên cứu của chúng tôi ghi nhận mối liên quan giữa rối loạn trầm cảm mức độ nhẹ và tái nghiện rượu. Rối loạn trầm cảm mức độ nhe có mối quan hệ độc lập với khả năng tái nghiện rượu, làm tăng khả năng tái nghiện lên gấp 10,18 lần, với độ tin cậy 95\% CI $(1,46$ - 71,04), $\mathrm{p}<0,05$. Nghiên cứu của Korlakunta và cộng sự (2012) cũng nhận thấy trầm cảm làm tăng nguy cơ tái nghiện rượu ${ }^{8}$. Vì vậy, việc phát hiện, điều trị sớm và đồng thời trầm cảm ở những bệnh nhân nghiện rượu sẽ góp phần làm giảm nguy cơ tái nghiện.

\section{KẾT LUÂNN}

- 71,29\% đối tượng tham gia nghiên cứu đã tái nghiện rượu sau khi ra viện, tỷ lệ tái nghiện cao nhất trong tháng đầu sau khi điều trị $(35,64$ $\%)$, lý do tái nghiện rượu chủ yếu là do thèm nhớ (76,39\%).

- Tiền sử gia đình có người lạm dụng, nghiện rượu, gia đình bệnh nhân không phản đối việc sử dụng rượu, sang chấn tâm lý và sự xuất hiện đồng thời rối loạn trâm cảm làm tăng khả năng tái nghiện rượu. Do đó các bệnh nhân sau khi đã cai nghiện rượu cần được điều trị chống tái nghiện lâu dài tại cộng đồng.

\section{TÀI LIỆ THAM KHẢO}

1. World Health Organization, Management of Substance Abuse Unit. Global Status Report on Alcohol and Health, 2018. World Health Organization; 2018.

2. Walitzer KS, Dearing RL. Gender differences in alcohol and substance use relapse. Clin Psychol Rev. 2006; 26(2): 128-148. doi:10.1016/ j.cpr.2005.11.003

3. Henkel D. Unemployment and Substance Use: A Review of the Literature (1990-2010). Curr Drug Abuse Rev. 2011;4(1):4-27. doi:10.2174/ 1874473711104010004

4. Benjamin J. Sadock, M.D., Virginia A. Sadock, M.D., Pedro Ruiz, M.D. Substance Related Disorders. In: Kaplan \& Sadock's Comprehensive Textbook of Psychiatry. Vol I/II. Tenth. Wolters Kluwer; 2017.

5. Evren C, Durkaya M, Evren B, Dalbudak E, Cetin R. Relationship of relapse with impulsivity, 
novelty seeking and craving in male alcoholdependent inpatients: Impulsivity, novelty seeking and craving. Drug Alcohol Rev. 2012;31(1):81-90. doi:10.1111/j.1465-3362.2011.00303.x

6. Walter $\mathbf{M}$, Gerhard $\mathbf{U}$, Duersteler-MacFarland KM, Weijers H-G, Boening J, Wiesbeck GA. Social Factors but Not Stress-Coping Styles Predict Relapse in Detoxified Alcoholics. Neuropsychobiology. 2006; 54(2):100-106. doi:

\subsection{9/000096991}

7. Sureshkumar K, Kailash S, Dalal PK, Reddy MM, Sinha PK. Psychosocial Factors Associated with Relapse in Patients with Alcohol Dependence. Indian J Psychol Med. 2017;39(3):312-315. doi:10.4103/0253-7176.207337

8. Korlakunta A, Chary RSS, Reddy CM P. Reasons for relapse in patients with alcohol dependence. AP J Psychol Med. 2012;13(2):108-4.

\section{NGHIÊN CỨU GIÁ TRI CộNG HƯỞNG TỪ TRONG ĐÁNH GIÁ BILAN XÂM LẤN VÙNG CỦA UNG THƯ CỔ TỬ CUNG}

\section{TÓM TẮT}

Mục đích: Đánh giá vao trò của chụp cộng hưởng từ tiểu khung đối với xâm lấn vùng của ung thư cổ tử cung. Đối tượng và phương pháp nghiên cứu: Bệnh nhân được chẩn đoán ung thư cổ tử cung, được chụp CHT 1.5T theo protocol chup tử cung có tiêm thuốc đối quang, sauu đó được phấu thuật cắt bỏ đánh giá kết quả giải phẫu bênh, từ đó so sánh để đánh giá giá trị của cộng hưởng từ. Kết quả: Có 47 bệnh nhân ung thư cổ tử cung được chụp $\mathrm{CHT}$ và phẫu thuật so sánh, trong đó có 4 trường hợp xâm lấn âm đạo, 21 trường hợp xâm lấn dây chằng rộng, 1 trường hợp xâm lấn bàng quang, 1 trường hợp xâm lấn trực tràng, 2 trường hợp có di căn hạch tiểu khung. Giá trị của cộng hưởng từ trong chấn đoán các đặc điểm trên có độ nhạy và độ đặc hiệu, giá trị dự báo dương tính, giá trị dưới báo ẩm tính rất cao, từ 95,7\% đến 100\%. Kết luận: Cộng hưởng từ có giá trị cao trong đánh giá bilan xâm lấn vùng của ung thư cổ tử cung

Tư khóa: cổ tử cung, ung thư, cộng hưởng từ.

\section{SUMMARY}

\section{RESEARCH ON MRI VALUES IN INVASIVE}

ASSESSMENT OF CERVICAL CANCER

Objective: evaluate role of pelvic MRI in invasive assessment of cervical cancer. Material and method: patients with diagnosis of cervical cancer underwent MRI 1.5T with contrast enhancement pre surgery. The pathology result post procedure then were compared to MRI diagnosis to identify MRI value. Result: In 47 cervical cancer patients in our study, there were 4 cases with vaginal invasive, 21 cases with broad ligament, 1 case with bladder invasive, 1 case with rectal invasive, 2 cases with pelvic nodule metastasis. Post analysis, MRI value was identified with all charactersitic (Sn, Sp, PPV, NPV) ranging from $95.7 \%$ to $100 \%$. Conclusion MRI has

\footnotetext{
${ }^{1}$ Trung tâm Điện quang, Bệnh viện Bạch Mai ${ }^{2}$ Bệnh viên U bướu Hà Nội

Chịu trách nhiệm chính: Trần Anh Tuấn

Email: Bs.trananhtuan@yahoo.com.vn

Ngày nhận bài: 28.12.2020

Ngày phản biện khoa học: 26.2.2021

Ngày duyệt bài: 9.3.2021
}

\section{Trần Anh Tuấn ${ }^{1}$, Trần Lệ Quyên ${ }^{2}$}

very high value in invasive assessment of cervical cancer Keys words; cervical cancer, MRI value...

\section{I. ĐĂT VẤN ĐỀ}

Hiện nay nhờ có chụp cộng hưởng từ $(\mathrm{CHT})$ việc phân loại, đánh giá giai đoạn ung thư (UT) cổ tử cung (CTC) trở nên chính xác hớn. CHT có độ phân giải cao trong đánh giá mô mềm, hơn nữa với nhiều chuỗi xung, có thể quan sát ở nhiều hướng cắt nên có thể xác định rõ khối u nguyên phát từ GĐ sớm, đồng thời đánh giá rất tốt mức độ xâm lấn của khối u. Trong phân loại giai đoạn UT CTC cộng hưởng từ có độ chính xác từ $85-96 \% \%^{(1,2,3)}$.

\section{II. ĐỐI TƯợNG VÀ PHƯƠNG PHÁP NGHIÊN CỨU}

2.1. Tiêu chuẩn lựa chọn: Bệnh nhân được chẩn đoán là ung thư biểu mô cổ tử cung, chụp CHT máy 1.5T đánh giá bilan, được phẫu thuật điều trị đồng thời làm mô bệnh học để so sánh

2.2. Địa điểm và phương pháp nghiên cứu

Đia điểm nghiên cứu: Khoa chẩn đoán hình ảnh, bệnh vện U bướu Hà Nội

Thiết kế nghiên cứu: Nghiên cứu mô tả có so sánh, chọn mẫu không xác suất

Phương tiện nghiên cứu: Máy chụp $\mathrm{CHT}$ Siemens Essenza 1.5 Tesla

Kỹ thuật chụp CHT tiểu khung

+ Chuẩn bị bệnh nhân

- Thụt khoảng $20 \mathrm{ml}$ gel siêu âm vào âm đạo

+ Kỹ thuât:

- Chuỗi xung T2W và T2W xóa mõ cắt đứng dọc (sagittal) theo trục CTC (SPAIR: Ti $=80$ 120 ), độ dày lát cắt $3 \mathrm{~mm}$, khoảng cách giữa các lát cắt $0,3 \mathrm{~mm}$.

- Chuỗi xung $T 2 W$ và $T 2 W$ xóa mõ cắt chếch ngang (axial oblique) so với trục cơ thể qua vùng tiểu khung sao cho đạt được hướng ngang (axial) theo trục $\mathrm{CTC}$, đô dày lát cắt $3 \mathrm{~mm}$, khoảng cách giửa các lát cắt $0,3 \mathrm{~mm}$. 